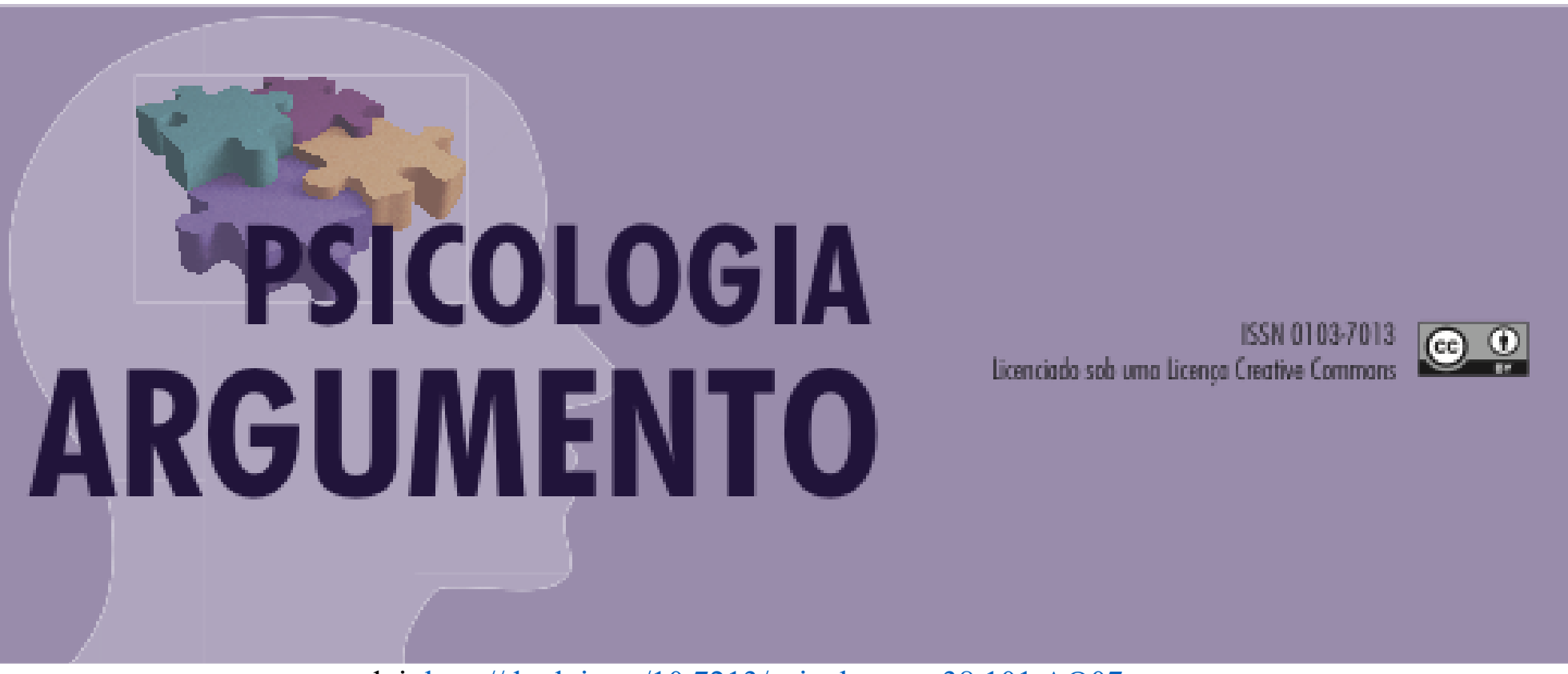

doi: http://dx.doi.org/10.7213/psicolargum.38.101.AO07

\title{
Mapeamento da produção científica brasileira sobre segmentação moral pelo estado da arte
}

Mapping of Brazilian scientific production on moral segmentation by the state of the art

Mapeo de la producción científica brasileña sobre segmentación moral por el estado del arte

\author{
Matheus Estevão Ferreira da Silva \\ Universidade Estadual Paulista (UNESP) - Campi de Marília e de Assis, e-mail: \\ matheus.estevao2@hotmail.com \\ ORCID: https://orcid.org/0000-0002-2059-6361
}

Patrícia Unger Raphael Bataglia

Universidade Estadual Paulista (UNESP) - Campus de Marília, e-mail:

patriciaurbataglia@gmail.com

ORCID: https://orcid.org/0000-0002-2575-3020

\begin{abstract}
Resumo
O objetivo deste artigo foi mapear a produção de pesquisa científica brasileira sobre segmentação moral por meio do estado da arte. O mapeamento consistiu no levantamento de materiais de divulgação de pesquisas em dois formatos: 1) artigos e 2) teses e dissertações. Utilizando-se dos descritores "segmentação moral" e "competência moral", o levantamento dos artigos foi feito no Portal da CAPES, SciELO e Google Acadêmico, enquanto das teses e dissertações no Catálogo da CAPES, BDTD e, novamente, Google Acadêmico. Aplicados os critérios de seleção, totalizaram-se 04 artigos e 30 teses e dissertações. Seguiu-se com o mapeamento analisando as seguintes variáveis dos materiais: autoria e periódico (artigos), orientação, área disciplinar, instituição e região de origem (teses e dissertações), ano de publicação e metodologia aplicada (ambos). Constatada a escassez da produção, aponta-se para a necessidade de mais pesquisas sobre segmentação moral ou sobre competência moral, mas com a segmentação como objeto de análise.
\end{abstract}


Palavras-chave: segmentação moral; competência moral; estado da arte.

\begin{abstract}
This article maps the production of Brazilian scientific research on moral segmentation through the state of the art. The mapping consisted of surveying research dissemination materials in two formats: 1) articles and 2) theses and dissertations. Using the descriptors "moral segmentation" and "moral competence", the survey of the articles was done on the CAPES Portal, SciELO and Google Scholar, while the theses and dissertations in the CAPES Catalog, BDTD and, again, Google Scholar. After applying the selection criteria, there were a total of 04 articles and 30 theses and dissertations. The mapping followed by analyzing the following variables of the materials: authorship and periodical (articles), orientation, disciplinary area, institution and region of origin (theses and dissertations), year of publication and applied methodology (both). Given the scarcity of production, there is a need for more research on moral segmentation or on moral competence, but with segmentation as an object of analysis.
\end{abstract}

Keywords: moral segmentation; moral competence; state of the art.

\title{
Resumen
}

Este artículo mapea la producción de la investigación científica brasileña sobre segmentación moral por estado del arte. El mapeo consistió en materiales topográficos para la difusión de la investigación en dos formatos: 1) artículos y 2) tesis y disertaciones. Utilizando los descriptores "segmentación moral" y "competencia moral", y se realizó en el Portal CAPES, SciELO y Google Scholar, mientras que las tesis y disertaciones en el Catálogo CAPES, BDTD y, nuevamente, Google Scholar. Aplicando los criterios de selección, hubo un total de 04 artículos y 30 tesis y disertaciones. El mapeo siguió analizando las siguientes variables de los materiales: autoría y publicación periódica (artículos), orientación, área disciplinaria, institución y región de origen (tesis y disertaciones), año de publicación y metodología aplicada (ambos). Dada la escasez de producción, existe la necesidad de más investigación sobre la segmentación moral o sobre la competencia moral, pero con la segmentación como objeto de análisis.

Palabras clave: segmentación moral; competencia moral; estado del arte.

\section{Introdução}

A competência moral é um conceito cunhado pelo psicólogo estadunidense Lawrence Kohlberg (2017) e se refere à capacidade de uma pessoa avaliar situações complexas não com base em sua posição a favor ou contrária ao tema em discussão, mas levando em consideração o valor dos argumentos opostos à sua própria opinião. Contudo, a competência moral foi apenas anunciada por Kohlberg no âmbito de sua teoria do desenvolvimento moral, sendo retomada e operacionalizada por Georg Lind (2019).

$\mathrm{Na}$ década de 1970, Lind desenvolveu um instrumento fechado que mensura a competência moral com base na teoria de Kohlberg, o Moral Competence Test (MCT). Esse instrumento foi trazido ao Brasil, sendo traduzido, adaptado e validado, por Bataglia (2001) no final da década de 1990 e início dos anos 2000. Contudo, desde essa primeira pesquisa de validação (Bataglia, 2001), assim como nas pesquisas seguintes que 
procuraram aprimorar essa primeira versão validada do MCT (Bataglia, 2010; Bataglia, Schillinger-Agati, Torres, Crivelaro, Oliveira, \& Quevedo, 2002; Bataglia, SchillingerAgati, Lind, \& Quevedo, 2003; Bataglia, Schillinger, \& Lind, 2006), identificou-se a ocorrência de um fenômeno que ficou conhecido como segmentação do juízo moral.

Assim, de acordo com a relação apresentada entre os escores do instrumento, denominou-se de segmentação moral o fenômeno de queda da qualidade moral na resolução de dilemas morais que compõem o MCT quando esses apresentam conteúdo específico relacionado a um tema que afeta o respondente. Naquela época, este mesmo fenômeno também foi observado em outros países da América Latina, como por Lind (2003) na Colômbia e por Moreno (2005) entre estudantes mexicanos. Ademais, nessas pesquisas seguintes aqui citadas (Bataglia, 2010; Bataglia et al., 2002; 2003; 2006), em que a segmentação moral se reafirmou, uma versão estendida do MCT foi desenvolvida, o MCT_xt (Moral Competence Test extended), visando melhor compreensão do fenômeno da segmentação.

Ressalta-se que o estudo da segmentação moral tem relevância tanto científica quanto social, tendo em vista que esse fenômeno pode estar relacionado a posturas dogmáticas, extremistas e, até, à resolução de conflitos com uso da violência mais do que por meio do diálogo. Isso interessa para a educação na medida em que pode considerar esse fator na elaboração de estratégias de trabalho que desenvolvam as competências democráticas, com o uso de metodologias ativas e reflexivas. Interessa ainda do ponto de vista social porque para a vida cidadã tais características (reflexividade, flexibilidade, respeito e capacidade de diálogo) são mais do que desejáveis, são necessárias.

Passados 20 anos desde a primeira pesquisa que o validou no Brasil (Bataglia, 2001), o MCT segue em uso no país em pesquisas sobre moralidade, tanto em sua versão original quanto estendida. Não se sabe ao certo, contudo, o estado atual das evidências sobre a segmentação moral nessas pesquisas que utilizam o MCT, se há pesquisas que continuam a encontrar esse fenômeno e qual o seu panorama no contexto da produção de pesquisa científica brasileira sobre moralidade.

Assim, para inteligibilidade dessa produção e reconhecimento de seu estado atual, o objetivo deste artigo foi mapear a produção de pesquisa científica brasileira sobre segmentação moral por meio do estado da arte (Ferreira, 2002; Romanowski \& Ens, 2006; Maciel, 2014). Recorrendo-se à pesquisa bibliográfica como percurso 
metodológico, adicionou-se a técnica de estado da arte para guiá-la no que tange ao mapeamento da produção em questão.

Ademais, o trabalho de pesquisa relatado neste artigo foi culminado a partir do encontro de interesses de duas pesquisas em andamento, uma desenvolvida em nível de Mestrado $^{1}$ pelo primeiro autor e outra em nível de Livre-Docência ${ }^{2}$ pela segunda autora, orientadora da pesquisa de Mestrado. Abordam-se, aqui, resultados parciais obtidos com essa colaboração científica.

Para que isso seja possível, o texto deste artigo foi organizado da seguinte forma: primeiro, abordam-se os conceitos de competência moral, de acordo com o que o MCT mensura, e de segmentação moral, discutindo os achados da pesquisa de validação do MCT e dos estudos seguintes feitos no Brasil que levaram à hipótese da segmentação, então confirmada em contexto maior, levando-se em conta sua presença em outros países latino-americanos. Em seguida, discutem-se os procedimentos que consistiram no estado da arte para o mapeamento da produção sobre segmentação moral.

A primeira parte do mapeamento consistiu no levantamento dos materiais de divulgação das pesquisas científicas brasileiras em dois de seus principais formatos: 1) artigos e 2) teses e dissertações. Utilizando-se dos descritores "segmentação moral" e "competência moral", o levantamento dos artigos foi feito no Portal de Periódicos da CAPES, Scientific Electronic Library Online (SciELO) e Google Acadêmico, enquanto das teses e dissertações no Catálogo de Teses \& Dissertações CAPES, Biblioteca Digital Brasileira de Teses e Dissertações (BDTD) e, novamente, Google Acadêmico. Na segunda parte do mapeamento seguindo o estado da arte, os materiais encontrados foram analisados a partir das seguintes variáveis: no caso dos artigos, autoria e periódico em que foi veiculado, no caso das teses e dissertações, orientação, área disciplinar, instituição e região de origem, e, em ambos os casos, ano de publicação e metodologia aplicada.

Por fim, apresentam-se os resultados obtidos com o mapeamento pelo estado da arte. Ao todo, foram encontrados 08 artigos e 43 teses e dissertações. Aplicados os critérios de seleção (inclusão e exclusão) dos materiais, totalizaram-se 04 artigos e 30

\footnotetext{
${ }^{1}$ Essa primeira pesquisa intitula-se Competência moral, gênero e sexualidades, e religiosidade na formação inicial pública paulista em Pedagogia e Psicologia, com financiamento do Conselho Nacional de Desenvolvimento Científico e Tecnológico (CNPq) pelo processo n. ${ }^{\circ}$ 131735/2020-9 e vigência prevista de 01/03/2020 a 28/02/2022.

${ }^{2}$ Intitulada Competência moral: contribuição para a elaboração do constructo, a tese produzida a partir dessa pesquisa para obtenção do título de livre-docente em Psicologia do Desenvolvimento Moral, edital n. ${ }^{\circ}$ 28/2020-CM, está com sua defesa prevista para este ano de 2020.
} 
teses e dissertações. Entre os principais resultados, ressalta-se, de antemão, que a produção investigada é escassa; há picos e baixas no decorrer dos anos, mas sem relação de ascendência a curto prazo; mostrou-se concentrada nas regiões sul e sudeste e em instituições públicas de pesquisa; e se trata de investigação empírica em sua maioria.

\section{Moral Competence Test (MCT) e o problema da segmentação moral}

Lawrence Kohlberg (2017) dedicou seus estudos e pesquisas à descrição de estágios morais dentro de sua teoria do desenvolvimento moral, inclusive elaborando uma entrevista padronizada de avaliação qualitativa e quantitativa do juízo moral, a Moral Judgment Interview (MJ) (Colby \& Kohlberg, 1987). Esse instrumento, porém, volta-se apenas ao aspecto do juízo moral, assim como outros instrumentos de avaliação decorrentes, como o Socio-moral Reflection Objective Measure (SROM) de J. Gibbs (Souza, Souza, Bilsky, Roazzi, 2016) e o Defining Issues Test 2 (DIT-2) de J. Rest e colaboradores (Thoma, Bebeau \& Narvaez, 2016), instrumentos os quais seguem em uso em pesquisas sobre moralidade no Brasil, como ressaltam Bataglia, Morais e Lepre (2010).

Outros aspectos da moralidade, anunciados desde Piaget (1994) a quem Kohlberg retoma o trabalho e fundamenta sua teoria, como o sentimento e a ação moral, não foram o foco dos estudos de Kohlberg (2017) e nem de alguns de seus colaboradores(as) e outros(as) autores(as) por muito tempo. Ainda assim, no que tange a ação moral, Kohlberg deixou anunciado em sua teoria o constructo de competência moral.

Para Kohlberg (2017), agir moralmente depende do desenvolvimento de uma capacidade, a de refletir e aplicar consistentemente princípios em situações difíceis, dilemáticas. Quando nos defrontamos a essas situações que exigem de nós uma resposta e os cursos de ação possíveis são conflitantes e mutuamente excludentes, somos mobilizados afetivamente e, nesse momento, exibimos ou não a capacidade de agir de acordo com princípios, apesar da comoção. É essa capacidade que Kohlberg denominou competência moral.

Georg Lind (2019), pesquisador da Universidade de Konstanz, Alemanha, retomou esse construto e o aprofundou em pesquisas que desenvolveu nos últimos 
quarenta anos. Desses estudos, resultou-se o Moral Competence Test (MCT) ${ }^{3}$, instrumento fechado, elaborado desde a década de 1970 e atualizado ao longo dos anos (Lind \& Wakenhut, 2017), que avalia a competência moral com base na teoria de Kohlberg. Esse é o único dos instrumentos de avaliação do desenvolvimento moral (Bataglia et al., 2010) que trata do aspecto da ação moral, mais especificamente da competência moral. Vale ressaltar que a competência moral não trata da ação em si, mas sim da disposição para a ação, uma vez que a ação moral só pode ser observada em seu contexto de realização, e é, portanto, o mais próximo que se pode chegar da ação moral por meio de um teste psicológico psicométrico.

O MCT é composto originalmente por dois dilemas morais, o primeiro relacionado a uma situação trabalhista em que operários roubam documentos para denunciar a empresa em que trabalham e o segundo dilema relacionado à eutanásia (Lind \& Wakenhut, 2017). Após a leitura dos dilemas, o(a) respondente deve avaliar algumas alternativas, distribuídas em uma escala Likert, referentes a argumentos a favor e contra sua própria opinião e que carregam diversas orientações morais para resolução dos dilemas.

Desde a primeira aplicação desse instrumento no Brasil, na pesquisa que o validou e nas seguintes que o aprimoraram ${ }^{4}$, contudo, constatou-se a ocorrência do fenômeno da segmentação moral. Se a competência moral é definida como a capacidade de emitir juízos baseados em princípios e agir de acordo com eles, a segmentação moral, por sua vez, refere-se ao fenômeno de queda da qualidade moral na resolução de determinado dilema, no caso, a diminuição da capacidade de agir de acordo com princípios, quando esse dilema apresenta conteúdo relacionado a um tema que afeta o(a) respondente.

O termo segmentação moral foi usado inicialmente por Döbert e Nunner-Winkler (1978 citado por Senger, 1985), referindo-se a respostas em diferentes estágios morais dependendo das características do problema social envolvido. No caso do MCT, a segmentação se refere a como se comportam as respostas dadas para a resolução dos

\footnotetext{
${ }^{3} \mathrm{O}$ instrumento foi elaborado originalmente com o nome de Moral Judgement Interview (MJT), sendo renomeado para Moral Competence Test (MCT) em 2014. Sobre isso, ver Lind (2019). Disponível em: $<$ http://www.uni-konstanz.de/ag-moral/mut/mjt-engl.htm>.

${ }^{4}$ Para fins de inteligibilidade dessa trajetória e de registro, ressalta-se que essas pesquisas realizadas no início da década de 2000 (Bataglia, 2001; Bataglia, et al., 2002; 2003; 2006), já citadas neste artigo, na época haviam sido, em sua maioria, apresentadas como papers nas reuniões anuais internacionais da Association for Moral Education (AME). Porém, recentemente, elas tiveram sua descrição e principais resultados reunidos e publicados em um artigo único (Bataglia, 2010), também já citado neste artigo.
} 
dilemas que o compõe, as quais têm sua qualidade moral diminuída de acordo com o conteúdo do dilema.

Lind (2019) considerou que a segmentação pode estar relacionada à suspensão ou perda do raciocínio moral autônomo ou competência de juízo moral. No entanto, a perda da autonomia moral implica, em posições extremistas, não negociação de opiniões ou, até, perda da opinião diante de conflitos morais, fazendo com que questões morais controversas sejam resolvidas somente pelo uso da violência e da guerra civil. Em uma sociedade plural e democrática, o esperado era que os(as) participantes fossem capazes de se engajar em uma discussão sobre questões controversas e manter um discurso, sendo capazes de raciocinar moralmente, mesmo defronte a adversários.

Com a persistência desses baixos resultados, em comparação com os resultados obtidos na Alemanha e em outros países da Europa, observou-se que isso ocorria em relação a apenas um dos dilemas do MCT, relacionado a eutanásia. Este mesmo fenômeno também foi observado em outros países da América Latina, como por Moreno (2005) entre estudantes mexicanos e por Lind (2003) na Colômbia. Moreno (2005) apresentou um trabalho a respeito da análise que havia feito dos dilemas que compunham o MCT em separado. Foi possível identificar que no México, assim como no Brasil, a segmentação também ocorria somente em relação ao dilema da eutanásia e não ao dilema dos operários.

Como o dilema da eutanásia toca diretamente em um dogma religioso, levantouse a hipótese de influência do conteúdo religioso na capacidade de reflexão sobre problemas morais difíceis. Assim, a procura de melhor compreensão do fenômeno da segmentação do juízo moral, desenvolveu-se uma versão estendida do MCT, o MCT_xt (Bataglia et al., 2003; 2006). Com a versão estendida, manteve-se os dois dilemas originais e acrescentou-se um dilema chamado "dilema do juiz", cujo tema é a tortura de uma prisioneira em prol de possivelmente salvar a vida de 200 pessoas ameaçadas por um grupo terrorista. Esse novo dilema trata do valor da vida humana, mas não toca em um aspecto religioso como a eutanásia. Nas aplicações seguintes do instrumento, em que se acumula mais de 2.000 , persiste a segmentação e as correlações são positivas quando comparados os escores do dilema dos operários e o dilema do juiz e negativas quando o dilema da eutanásia é comparado com os demais. Assim, foi validado o dilema do juiz e passou-se, então, a sugerir aos(às) pesquisadores(as) brasileiros(as) que usem a versão estendida do instrumento, com 3 dilemas. 
Quanto às pesquisas brasileiras atuais sobre moralidade, e em específico à competência moral, pode-se dizer que "[...] faltam estudos que realizem um balanço e encaminhem para a necessidade de um mapeamento que desvende e examine o conhecimento já elaborado e apontem os enfoques, os temas mais pesquisados e as lacunas existentes" (Romanowski \& Ens, 2006, p. 38), sendo que esse tipo de balanço é, a propósito, o que fazem as pesquisas de estado da arte. Essa defasagem na inteligibilidade da produção fica ainda mais nítida no que diz respeito à segmentação moral, uma vez que não se sabe o estado em que se encontra na produção de pesquisa brasileira desde às pesquisas de validação realizadas no início da década de 2000 , então reunidas em Bataglia (2010).

Portanto, propôs-se suprir essa defasagem com o trabalho de pesquisa aqui relatado, elegendo-se a técnica de estado da arte para o mapeamento da produção de pesquisa científica brasileira sobre segmentação moral. Essa técnica foi considerada a mais apropriada para o cumprimento dos objetivos e critérios delineados, conforme se discute com maior profundidade no tópico a seguir.

\section{Metodologia: produção de pesquisa e seu reconhecimento pelo estado da arte}

A pesquisa científica é, hoje, parte das atribuições das Universidades e Institutos brasileiros (Nobre \& Freitas, 2017), sendo que as Universidades públicas, por sua vez, são responsáveis por mais de $95 \%$ da produção científica do Brasil. Das atividades que possibilitam esse quadro de alta produção, verifica-se o desenvolvimento de pesquisas na modalidade de Mestrado e Doutorado provenientes de Programas de Pós-Graduação (PPGs) vinculados às Universidades. Dessa forma, o trabalho de pesquisa que este artigo resulta teve essa produção de pesquisa em específico como foco de sua investigação.

Aqui, por produção de pesquisa, compreende-se tanto o processo - a pesquisa em si - quanto o resultado da pesquisa científica - o trabalho monográfico produzido a partir da pesquisa realizada como forma de divulgação de seus resultados -, como Trabalhos de Conclusão de Curso (TCCs) no caso da graduação, teses e dissertações no caso da pósgraduação stricto sensu, relatórios, artigos, etc.

Dentre esses formatos, os artigos são reconhecidos como a principal forma de divulgação de resultados de pesquisas (Almeida \& Guimarães, 2017; Nobre \& Freitas, 2017), sejam elas desenvolvidas em quaisquer modalidades (Iniciação Científica, 
Mestrado, Doutorado, etc.) ou já divulgadas em trabalho monográfico, como aquelas cujos resultados são divulgados em teses e dissertações, mas também publicados em artigos. Tendo isso em vista, a investigação aqui retratada também teve a produção de pesquisa em artigos como seu foco.

Traçado como objetivo o mapeamento da produção de pesquisa sobre segmentação moral, para a reunião dessa produção e sua posterior análise tivemos de eleger um caminho para nossa pesquisa bibliográfica seguir. O caminho reconhecido mais adequado foi aquele possibilitado pela técnica metodológica de estado da arte (Ferreira, 2002; Romanowski \& Ens, 2006; Maciel, 2014). Essa técnica é geralmente aderida por pesquisas que buscam o reconhecimento, a organização e a inteligibilidade da produção científica de determinado assunto que se faz objeto de investigação, no caso, a segmentação moral. Como ressalta Ferreira (2002, p. 258), as pesquisas denominadas de estado da arte apresentam:

[...] o desafio de mapear e de discutir uma certa produção acadêmica em diferentes campos do conhecimento, tentando responder que aspectos e dimensões vêm sendo destacados e privilegiados em diferentes épocas e lugares, de que formas e em que condições têm sido produzidas certas dissertações de mestrado, teses de doutorado, publicações em periódicos e comunicações em anais de congressos e de seminários.

Todavia, Maciel (2014, p. 110) considera que as pesquisas de estado da arte no Brasil recebem "[...] pouco incentivo das agências de fomento em financiá-las, assim como ao investimento do pesquisador em levar adiante uma pesquisa longitudinal e extensa, dadas as características intercontinentais de nosso país". Outrossim, também concordamos com a autora (2014, p. 110) quando ressalta que "essa falta de interesse também se relaciona com a pesquisa pura e aplicada, uma vez que o estado da arte não apresente uma aplicabilidade imediata, é apenas um balanço da produção", o que também pode ter relação com a pouca abertura de periódicos especializados em aceitar artigos que divulguem os resultados de investigações com esse caráter de apenas revisão da produção.

Portanto, o mapeamento possibilitado pelo estado da arte consistiu em duas partes inter-relacionadas, a primeira de levantamento da produção investigada e a segunda de sua análise. $\mathrm{Na}$ primeira parte, procedemos então a um levantamento das pesquisas científicas brasileiras sobre segmentação moral a partir dos materiais de divulgação dessas pesquisas em dois de seus principais formatos (e que são públicos para consulta): 1) artigos e 2) teses e dissertações. O levantamento foi feito por meio dos procedimentos de localização, recuperação, reunião, seleção e organização dos materiais encontrados. 
As bases de dados consultadas para o levantamento dos artigos foram o Portal de Periódicos CAPES, o Scientific Electronic Library Online (SciELO) e o Google Acadêmico, enquanto para as teses e dissertações as bases foram o Catálogo de Teses \& Dissertações da CAPES, a Biblioteca Digital Brasileira de Teses e Dissertações (BDTD) e, novamente, o Google Acadêmico.

Sem delimitação temporal, pois já se sabe que o fenômeno estudado foi encontrado no início dos anos 2000 e que se quer saber se ele continua a ser encontrado desde então, o descritor que guiou as buscas nessas bases foi único: "segmentação moral". Contudo, em algumas das bases, tanto referente a artigos quanto de teses e dissertações, não se encontrou nenhum resultado com esse descritor. Assim, recorreu-se ao descritor mais amplo "competência moral" apenas naquelas bases que não se encontraram resultados, selecionando materiais que tratam da competência moral nessa primeira etapa do estado da arte para posterior exclusão daqueles que não tratam da segmentação moral.

Com o levantamento, pôde-se produzir um instrumento de pesquisa que foi intitulado de Pesquisas brasileiras sobre segmentação moral em artigos e teses e dissertações (2001-2019): um instrumento de pesquisa (Silva \& Bataglia, 2020), documento que reúne as referências dos materiais encontrados com o levantamento. Ao todo, foram 08 artigos encontrados, sendo alguns deles duplicados entre as bases, e 43 teses e dissertações, alguns também duplicados. Assim, até um primeiro momento, nele constaram 51 referências dos materiais referentes a produção sobre segmentação moral.

Há ainda de se pontuar que, em variância terminológica, nas pesquisas de estado da arte, os instrumentos de pesquisa podem ser denominados de catálogos. Como ressalta Ferreira (2002, p. 261), instrumentos de pesquisa, ora catálogos, “[...] trazem os títulos das dissertações de mestrado e teses de doutorado, mas também os dados identificadores de cada pesquisa quanto aos nomes do autor e do orientador, do local, data da defesa do trabalho, da área em que foi produzido", isto é, dados bibliográficos retirados das próprias dissertações e teses e dos artigos, tratados como fontes, e inseridos no documento em criação, tal como fizemos na confecção de nosso instrumento de pesquisa.

A segunda parte do mapeamento iniciou-se em relação direta ao encerramento da anterior, em que se criou o instrumento. Consistiu, primeiramente, na aplicação de um critério de exclusão: uma vez que se utilizou do descritor mais geral "competência moral", excluíram-se aqueles materiais que não tratavam da segmentação moral, além de que mesmo com a busca pelo descritor "segmentação moral" alguns dos materiais 
encontrados também não se referiam ao fenômeno aqui estudado, os quais também foram excluídos para compor esta segunda parte do estado da arte.

Em seguida à aplicação do critério de seleção, em que se atualizou o instrumento de pesquisa quanto à exclusão das pesquisas que não tratam da segmentação moral, analisaram-se os materiais restantes a partir das seguintes variáveis: no caso dos artigos, autoria e periódico em que foi veiculado, no caso das teses e dissertações, orientação, área disciplinar, instituição e região de origem, e, em ambos os casos, ano de publicação e metodologia aplicada. Os resultados encontrados com essa análise, bem como mais detalhes sobre o levantamento realizado, são apresentados a seguir.

\section{Resultados: mapeamento das pesquisas brasileiras sobre segmentação moral}

Seguindo-se com a explanação dos resultados referente a primeira parte do mapeamento, analisamos inicialmente a procedência dos resultados encontrados com as buscas feitas nas bases de dados, que indicou a duplicação de materiais entre as bases, tanto artigos como teses e dissertações, conforme indica o quadro disposto a seguir.

Quadro 1.

Resultados das buscas nas bases de dados Portal CAPES, SciELO e Google Acadêmico, quanto aos artigos, e Catálogo CAPES, BDTD e Google Acadêmico, quanto às teses e dissertações

\begin{tabular}{|l|l|l|l|l|}
\hline \multirow{2}{*}{ Estratégia de busca } & \multicolumn{4}{|l|}{ Quantidade de artigos encontrados } \\
\cline { 2 - 5 } & $\begin{array}{l}\text { Portal } \\
\text { CAPES }\end{array}$ & SciELO & $\begin{array}{l}\text { Google } \\
\text { Acadêmico }\end{array}$ & Total \\
\hline Segmentação moral & 1 & 0 & 5 & 6 \\
\hline Competência moral & 0 & 4 & 0 & 4 \\
\hline Total & 1 & 4 & 5 & 10 \\
\hline
\end{tabular}

\begin{tabular}{|l|l|l|l|l|l|l|}
\hline \multirow{3}{*}{$\begin{array}{l}\text { Estratégia de } \\
\text { busca }\end{array}$} & \multicolumn{6}{|l|}{ Quantidade de teses e dissertações encontradas } \\
\cline { 2 - 7 } & \multicolumn{2}{|l|}{ Catálogo CAPES } & \multicolumn{2}{l|}{ BDTD } & \multicolumn{2}{l|}{ Google Acadêmico } \\
\cline { 2 - 7 } & Teses & Dissert. & Teses & Dissert. & Teses & Dissert. \\
\hline Segmentação moral & 0 & 0 & 3 & 7 \\
\hline Competência moral & 8 & 32 & 3 & 10 & 0 & \\
\hline Total & 40 & 13 & & 10 & \\
\hline
\end{tabular}

Fonte: Dados da pesquisa 
No caso dos artigos, embora tenham sido, ao todo, 10 resultados entre as buscas feitas nas bases, como mostra o Quadro 1, no final foram 08 artigos diferentes encontrados, pois esses se repetiram nas buscas, sendo um mesmo artigo encontrado em mais de uma base de dados. Desses artigos, 03 foram encontrados somente no SciELO, 03 somente no Google Acadêmico, 01 foi encontrado tanto no SciELO como no Google Acadêmico, e 01 tanto no Google Acadêmico como no Portal de Periódicos da CAPES. Além disso, com o descritor "segmentação moral" foram encontrados 01 artigo no Portal da CAPES e 05 no Google Acadêmico, enquanto no SciELO, por não se ter encontrado nenhum resultado com esse descritor, aplicou-se o descritor "competência moral" encontrando-se 04 artigos nessa base.

Já no caso das teses e dissertações, ao todo foram 43 materiais diferentes encontrados, muitos também duplicados entre as bases de dados. Com o descritor "segmentação moral", foram encontrados materiais apenas no Google Acadêmico, 03 teses e 07 dissertações. Aplicando-se o descritor "competência moral", encontraram-se 08 teses e 32 dissertações no Catálogo de Teses \& Dissertações da CAPES e 03 teses e 10 dissertações na Biblioteca Digital Brasileira de Teses e Dissertações (BDTD). A duplicação entre as bases se deu com 10 materiais encontrados tanto no Catálogo da CAPES como na BDTD, 05 encontrados tanto na CAPES como no Google Acadêmico e 02 tanto no Catálogo da CAPES como na BDTD e Google Acadêmico.

Voltando-se agora à aplicação do critério de exclusão já anunciado, no grupo de artigos retiramos do mapeamento 04 artigos que não se referiam ao fenômeno da segmentação moral. Restaram outros 04 artigos, apresentados no quadro a seguir.

Quadro 2. 
Artigos selecionados que abordam a segmentação moral encontrados nas bases Portal de Periódicos CAPES, Scientific Electronic Library Online (SciELO) e Google Acadêmico

\begin{tabular}{|c|c|c|c|c|}
\hline Autor & Título & Periódico & Ano & Base \\
\hline $\begin{array}{l}\text { Bataglia, P. U. R., } \\
\text { Morais, A. de., \& } \\
\text { Lepre, R. M. }\end{array}$ & $\begin{array}{l}\text { A teoria de Kohlberg sobre o } \\
\text { desenvolvimento do raciocínio } \\
\text { moral e os instrumentos de } \\
\text { avaliação de juízo e } \\
\text { competência moral em uso no } \\
\text { Brasil }\end{array}$ & $\begin{array}{l}\text { Estudos } \\
\text { Psicologia }\end{array}$ & 2010 & $\begin{array}{l}\text { SciELO } \\
\text { Google } \\
\text { Acadêmico }\end{array}$ \\
\hline $\begin{array}{l}\text { Feitosa, H. N., } \\
\text { Rego, S., Bataglia, } \\
\text { P. U. R., Rego, G., } \\
\text { \& Nunes, R. }\end{array}$ & $\begin{array}{l}\text { Competência de juízo moral } \\
\text { dos estudantes de medicina: } \\
\text { um estudo piloto }\end{array}$ & $\begin{array}{l}\text { Revista Brasileira } \\
\text { de } \quad \text { Educação } \\
\text { Médica }\end{array}$ & 2013 & $\begin{array}{l}\text { Portal de } \\
\text { Periódicos } \\
\text { CAPES / } \\
\text { Google } \\
\text { Acadêmico }\end{array}$ \\
\hline $\begin{array}{l}\text { Landim, T. P., } \\
\text { Silva, M. S. F. da, } \\
\text { Feitosa, H. N., \& } \\
\text { Nuto, S. de A. S. }\end{array}$ & $\begin{array}{l}\text { Competência de juízo moral } \\
\text { entre estudantes de } \\
\text { Odontologia }\end{array}$ & $\begin{array}{l}\text { Revista Brasileira } \\
\text { de } \quad \text { Educação } \\
\text { Médica }\end{array}$ & 2015 & $\begin{array}{l}\text { Google } \\
\text { Acadêmico }\end{array}$ \\
\hline $\begin{array}{l}\text { Melo, N. W. de, } \\
\text { Souza, E., \& } \\
\text { Barbosa, L. }\end{array}$ & $\begin{array}{l}\text { Competência moral e } \\
\text { espiritualidade na educação } \\
\text { médica: realidade ou desafio }\end{array}$ & $\begin{array}{l}\text { Revista } \text { Brasileira } \\
\text { de } \quad \text { Educação } \\
\text { Médica }\end{array}$ & 2015 & $\begin{array}{l}\text { Google } \\
\text { Acadêmico }\end{array}$ \\
\hline
\end{tabular}

Fonte: Dados da pesquisa

Notada a escassez da produção sobre a segmentação moral em formato de artigos, tendo em vista que uma delimitação temporal sequer foi aplicada, o Quadro 2 apresenta os artigos encontrados tal como são referenciados no instrumento de pesquisa elaborado, aglutinando em um único quadro todas as variáveis aqui pertinentes para análise dessa produção: no caso dos artigos, ano de publicação, autoria, periódico em que foi publicado, base de dados em que foi encontrado e, discutida no corpo do texto, metodologia aplicada.

Assim, observa-se que as pesquisas sobre segmentação moral começaram a ser divulgadas como artigo em periódicos a partir do ano de 2010, com a publicação do artigo de Bataglia et al. (2010). Publicado em periódico da área de Psicologia, esse artigo foi encontrado nas bases SciELO e Google Acadêmico e retrata resultados de uma investigação teórica sobre os instrumentos de avaliação de juízo e competência moral em uso no Brasil, sendo o MCT um dos instrumentos abordados. 
Publicado em 2013, o artigo seguinte, de Feitosa et al. (2013), foi veiculado em periódico que intersecciona as áreas de Educação e Medicina, tendo sido encontrado nas bases Portal da CAPES e Google Acadêmico e que aborda resultados de um estudo piloto com estudantes de Medicina (N=113) utilizando-se do MCT como instrumento de coleta.

Os dois últimos artigos foram publicados em 2015, de Landim et al. (2015) e Melo, Souza e Barbosa (2015), no mesmo periódico que o artigo anterior, da área de Educação e Medicina, ambos encontrados apenas no Google Acadêmico e que abordam a segmentação moral em investigação empírica a partir do uso do MCT, também como instrumento de coleta. Apenas a amostra das duas pesquisas retratadas nesses artigos que variam, a primeira referindo-se a estudantes de Odontologia $(\mathrm{N}=280)$ e a segunda a estudantes de Medicina $(\mathrm{N}=121)$. Ressalta-se, ainda, que em todos 04 artigos, a segmentação moral é abordada apenas como uma variável de suas pesquisas, seja em abordagem teórica como no primeiro artigo, seja enquanto evidência empírica como nos três seguintes, e não como o tema central das investigações que realizaram.

Com relação às teses e dissertações, aplicado o critério de exclusão, em que se buscou a abordagem da segmentação moral por esses materiais, excluíram-se 13 deles do montante final, restando 30 trabalhos, sendo 10 teses e 20 dissertações, as quais são apresentadas quanto ao seu ano de publicação no gráfico que se segue. Antes, ressalta-se que pela extensão desses materiais em detrimento dos artigos, não disporemos todas as variáveis de análise em um único quadro, sendo analisadas separadamente no texto do artigo e/ou em um quadro (ou figura, como a seguir) respectivo a cada uma delas: no caso das teses e dissertações, ano de publicação, área disciplinar, instituição e região de origem, orientação, e metodologia aplicada.

Como se pode observar na Figura 1, a produção começa a datar em 2001 e vai até 2019, ano anterior a presente investigação feita nas bases de dados. Nos 19 anos desse período apenas em 12 anos houve a publicação de uma ou mais pesquisas sobre a segmentação moral. Além disso, o primeiro material, publicado em 2001 e disposto isoladamente no início da década de 2000 (visto que nos anos seguintes, até 2008, não houve a publicação de qualquer outro material), refere-se a tese de doutorado de Bataglia (2001) que trouxe ineditamente o constructo da competência moral ao Brasil, bem como a constatação sobre a segmentação moral com o MCT. O material seguinte, uma dissertação de Mestrado, que trata do fenômeno aqui estudado só surge então anos depois, em 2008. 


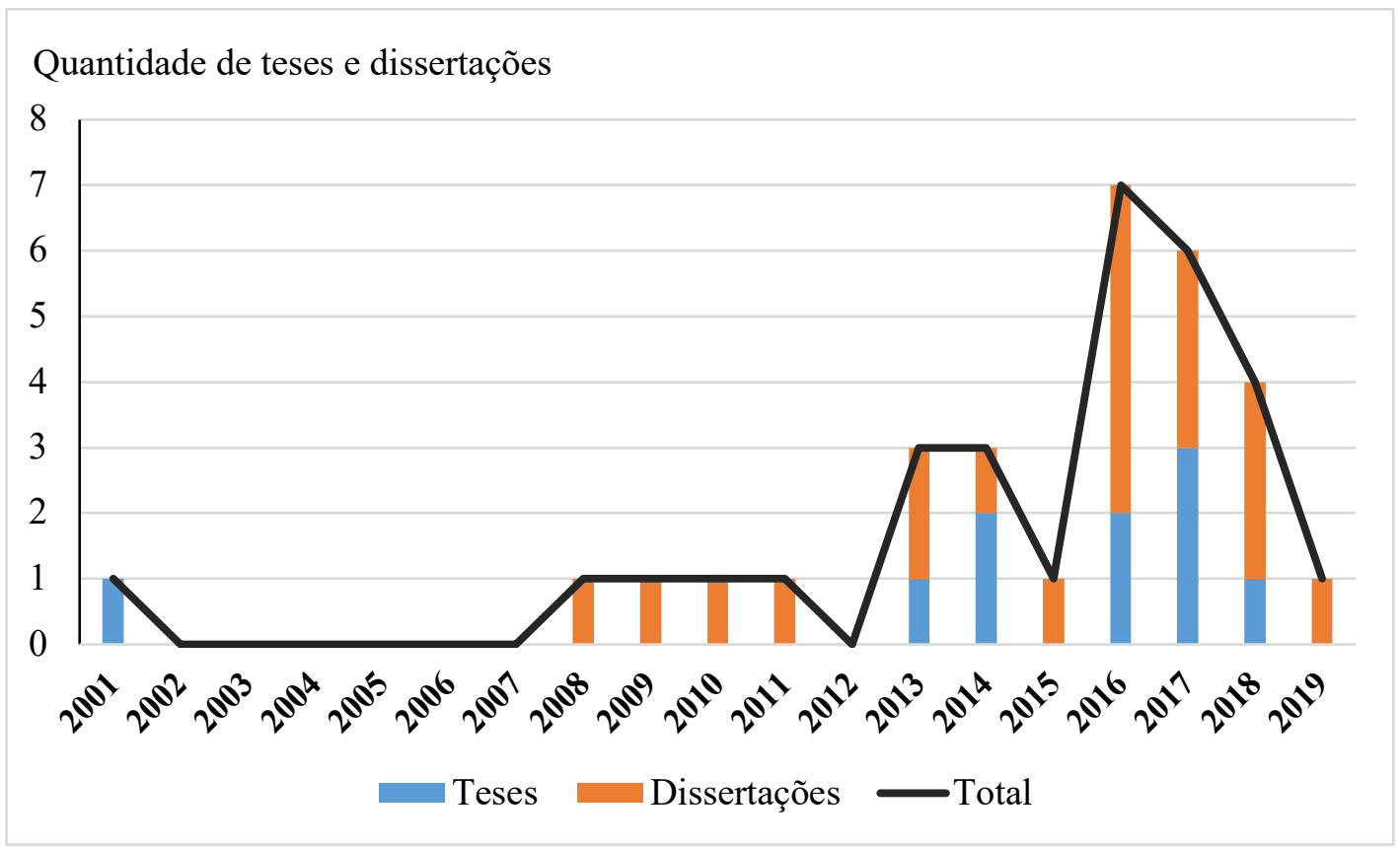

Figura 1.

Quantidade de teses e dissertações encontradas sobre segmentação moral segundo o ano de publicação em gráfico de barras e linha. Fonte: Dados da pesquisa

Considerando o total de 30 materiais, a média que se tira de publicações por ano no período 2001-2019 é de um material publicado por ano (com média exata de 1,5), enquanto se for considerado apenas os 12 anos em que houve publicação de teses e dissertações, a média é de dois materiais por ano (média exata de 2,5). Nota-se, portanto, a escassez da produção em teses e dissertações, não tanto em relação aos artigos como visto anteriormente, mas ainda assim escassa. Agora, observando especificamente cada ano do período 2001-2019, no intervalo entre os anos de 2016 e 2018 houve mais publicações em relação aos demais anos, com o pico do período em 2016, com 02 teses e 05 dissertações.

A variável seguinte analisada foi a instituição de origem dos materiais, mais especificamente, a Universidade, Faculdade ou Centro de Pesquisa que os Programas de Pós-Graduação (PPG), dos quais as teses e dissertações mapeadas provêm, vinculam-se, como mostra o Quadro 3 a seguir.

Quadro 3.

Quantidade de teses e dissertações encontradas sobre segmentação moral segundo sua origem institucional 


\begin{tabular}{|l|c|c|c|}
\hline Nome da instituição & Teses & Dissert. & Total \\
\hline $\begin{array}{l}\text { Centro Universitário das Faculdades Associadas de Ensino } \\
\text { (UNIFAE) }\end{array}$ & 0 & 1 & 1 \\
\hline Centro Universitário São Camilo & 1 & 0 & 1 \\
\hline Escola Nacional de Saúde Pública Sérgio Arouca (ENSP) & 1 & 5 & 6 \\
\hline Faculdade Pernambucana de Saúde (FPS) & 0 & 1 & 1 \\
\hline Faculdades Pequeno Príncipe (FPP) & 0 & 1 & 1 \\
\hline Universidade de Brasília (UnB) & 1 & 0 & 1 \\
\hline Universidade de Pernambuco (UPE) & 0 & 1 & 1 \\
\hline Universidade de São Paulo (USP) & 1 & 0 & 1 \\
\hline Universidade do Estado de Santa Catarina (UDESC) & 0 & 2 & 2 \\
\hline Universidade do Oeste Paulista (UNOESTE) & 0 & 1 & 1 \\
\hline Universidade Estadual de Campinas (UNICAMP) & 1 & 0 & 1 \\
\hline Universidade Estadual Paulista (UNESP) & 2 & 5 & 7 \\
\hline Universidade Federal de São Paulo (UNIFESP) & 1 & 0 & 1 \\
\hline Universidade Federal do Rio de Janeiro (UFRJ) & 1 & 0 & 1 \\
\hline Universidade Federal do Rio Grande (FURG) & 1 & 0 & 1 \\
\hline Universidade Federal Fluminense (UFF) & 0 & 1 & 1 \\
\hline Universidade Federal Rural do Rio de Janeiro (UFRRJ) & 0 & 1 & 1 \\
\hline Universidade José do Rosário Vellano (UNIFENAS) & 0 & 1 & 1 \\
\hline Total & 10 & 20 & 30 \\
\hline
\end{tabular}

Fonte: Dados da pesquisa

Os principais polos produtores - como podem ser chamadas as instituições responsáveis pela produção de pesquisa investigada - de teses e dissertações foram a Universidade Estadual Paulista (UNESP), com 02 teses e 05 dissertações, seguida da Escola Nacional de Saúde Pública Sérgio Arouca (ENSP), com 01 tese e 05 dissertações, e a Universidade do Estado de Santa Catarina (UDESC), com 02 dissertações, enquanto todos os outros polos apresentaram a produção de apenas um material, tese ou dissertação. Também considerável foi o número de instituições públicas em detrimento das particulares, visto que, como já mencionado, a Universidade pública, proeminente nesse quadro de instituições, é a principal instituição responsável pela pesquisa científica no Brasil (Nobre \& Freitas, 2017).

A próxima variável, região de origem, apresenta relação mais direta com a variável anterior do que com as demais, pois concerne a região geográfica da instituição de origem dos materiais. A partir dela, pode-se verificar se há a ocorrência do problema da concentração da produção de pesquisa e, por conseguinte, do conhecimento científíco 
em determinados territórios e regiões do país, conforme se mostrou historicamente presente e que em alguns contextos continua a ocorrer (Sidone, Haddad \& Mena-Chalco, 2016).

A região Sudeste foi considerada o principal polo produtor no quesito região/território, reunindo a maioria dos materiais, cerca de 08 teses e 15 dissertações, enquanto a região Sul reúne cerca de 01 tese e 03 dissertações e a Centro-Oeste somente 01 tese. A região Nordeste reúne apenas 02 dissertações enquanto não houve a incidência de materiais com origem na região Norte. Ressalta-se que esse resultado já era esperado não somente pela produção científica brasileira ter se concentrado historicamente nas mesmas regiões que a produção investigada se concentra, como também pelo fato das pesquisas com o MCT e, consequentemente, sobre a segmentação moral terem seu início na região Sudeste e que, por isso, tendem a continuar a ocorrer mais nessa região do que nas demais, principalmente pela pesquisadora responsável pela primeira dessas pesquisas (Bataglia, 2001) continuar, até hoje, a desenvolver e orientar pesquisas sobre o tema estando vinculada a uma Universidade, e a um de seus Programas de Pós-Graduação, localizada na região Sudeste, como mostrado mais adiante.

No que se refere às áreas do conhecimento que os materiais encontrados se enquadram, essas puderam ser identificadas por meio das áreas dos PPGs que as teses e dissertações provêm. Sendo a segmentação moral um fenômeno oriundo da Psicologia, com menor proximidade às demais Ciências, com surpresa verificou-se que essa não é área disciplinar que os materiais se enquadram predominantemente. Na verdade, a área predominante é a de Educação, em que 11 materiais se enquadram, 03 teses e 08 dissertações, seguida pela área de Saúde Pública com 06 materiais, 02 teses e 05 dissertações, e somente depois a Psicologia com 03 materiais, 01 tese e 02 dissertações. O restante dos materiais distribui-se entre as demais áreas: Ensino de Saúde, com 03 dissertações; Administração, com 02 dissertações; e Bioética, Ciências, Enfermagem e Processos de Desenvolvimento Humano e Saúde, cada uma com 01 tese cada.

Outra variável, que junto das variáveis de instituição e região de origem também auxilia em identificar a concentração da produção, é a orientação dada à pesquisa que resultou no material, tese ou dissertação, por um(a) pesquisador(a) do PPG em que se vincula, apresentada no quadro a seguir.

Quadro 4. 
Quantidade de teses e dissertações encontradas sobre segmentação moral segundo a orientação da pesquisa

\begin{tabular}{|l|l|l|l|}
\hline Orientador(a) & Teses & Dissertações & Total \\
\hline Alexandre de Araújo Pereira & 0 & 1 & 1 \\
\hline $\begin{array}{l}\text { Angela Maria Cristina Uchoa de Abreu } \\
\text { Branco }\end{array}$ & 1 & 0 & 1 \\
\hline Antônio Pereira Filho & 0 & 1 & 1 \\
\hline Benjamin Israel Kopelman & 1 & 0 & 1 \\
\hline Betânia Alves Veiga Dell' Agli & 0 & 1 & 1 \\
\hline Carmen Lúcia Dias & 0 & 1 & 1 \\
\hline Edvaldo Silva de Souza & 0 & 1 & 1 \\
\hline Geilsa Soraia Cavalcanti Valenti & 0 & 1 & 1 \\
\hline Marcio Fabri Dos Anjos & 1 & 0 & 1 \\
\hline Marcos Aguiar de Souza & 1 & 1 & 2 \\
\hline Maurício Custódio Serafim & 0 & 2 & 2 \\
\hline Patrícia Unger Raphael Bataglia & 1 & 2 & 3 \\
\hline Raul Aragão Martins & 1 & 3 & 4 \\
\hline Roberto Zonato Esteves & 0 & 1 & 1 \\
\hline Rosemary Silva da Silveira & 1 & 0 & 1 \\
\hline Sergio Tavares de Almeida Rego & 2 & 5 & 1 \\
\hline Telma Pileggi Vinha & 1 & 0 & 30 \\
\hline Zélia Ramozzi Chiarottino & 1 & 20 & 1 \\
\hline Total & 10 & 0 & 1 \\
\hline
\end{tabular}

Fonte: Dados da pesquisa

A partir do Quadro 4, infere-se que a maioria dos(as) orientadores(as) são homens, tomando-se como referência os 10 nomes masculinos, mas com pouca diferença em relação às mulheres, sendo 08 nomes femininos. Quem mais orientou as pesquisas desse montante investigado foi Sergio Tavares de Almeida Rego com 07 pesquisas no total, 02 teses e 05 dissertações, em seguida Raul Aragão Martins que orientou 04 pesquisas, 01 tese e 03 dissertações, e Patrícia Unger Raphael Bataglia que orientou 03 pesquisas, 01 tese 02 dissertações, sendo essa última a pesquisadora que trouxe o constructo da competência moral e constatação da segmentação ao Brasil (Bataglia, 2001).

A última variável analisada dos materiais refere-se à metodologia aplicada por essas pesquisas. Por sua vez, sem necessidade de expor os resultados da análise em 
formato de quadro, ressalta-se que apenas 06 materiais, 02 teses e 04 dissertações, não utilizam o MCT em suas investigações, portanto, que realizaram investigações teóricas, em âmbito bibliográfico, abordando a segmentação moral apenas como parte de revisão da literatura. Os 24 materiais restantes decorrem de investigações empíricas com o uso do MCT, ora aplicado sozinho, ora aliado a outros instrumentos de coleta para fim de análises comparativas entre a competência moral e outros constructos.

\section{Discussão: o que o mapeamento da produção brasileira pelo estado da arte revela sobre a segmentação moral?}

Após essa extensa análise, alguns aspectos sobre a produção de pesquisa brasileira puderam ser evidenciados e, assim, relevar o que se procurou responder quanto ao estado da segmentação moral nessa produção a partir do trabalho de pesquisa que deu origem ao presente artigo. Primeiro, observou-se a escassez de materiais, tanto artigos quanto teses e dissertações, cujas pesquisas neles retratadas abordam a segmentação moral. Comparando o presente mapeamento com outras investigações da literatura sobre moralidade, como de Dellazzana-Zanon, Bordini, Sperb e Freitas (2013) em que realizaram uma revisão de artigos empíricos sobre desenvolvimento moral no Brasil de 2000 a 2010, a produção investigada está muito aquém em termos de volume de produção.

Apenas selecionando artigos que tratam de pesquisas empíricas e com recorte temporal menor, Dellazzana-Zanon et al. (2013) reuniram cerca de 48 artigos, enquanto nosso levantamento encontrou apenas 04 artigos. Ainda assim, essa discrepância é compreensível devido ao presente mapeamento se tratar de um tópico específico da literatura sobre moralidade, visto que a competência moral já se trata de um tópico específico do amplo fenômeno da moralidade e a segmentação um tópico mais específico ainda, que decorre do anterior.

Com relação a temporalidade das pesquisas stricto sensu mapeadas (variável do ano de publicação), percebeu-se que a produção oscila ao longo do período de 2001 a 2019, com picos e baixas de produção sem relação de ascendência a curto prazo, pois só é possível verificar um aumento das pesquisas nos últimos anos e isso em detrimento do início do período em que havia incidência pouco significativa.

Não se pode inferir com precisão se a segmentação moral só se tornou um tópico de alta relevância nos últimos anos ou se esse aumento se deve a uma divulgação maior 
das pesquisas sobre competência moral, utilizando do MCT como instrumento de coleta, e, portanto, que despertou maior interesse por parte da comunidade científica. O que se pode dizer é que a demanda por pesquisas que tratam da competência moral e que tenham a segmentação como objeto de análise continua a ser solicitada, tendo em vista sua ainda contínua escassez na produção sobre moralidade no Brasil. E demanda que é solicitada não só do ponto de vista científico, como também social, em relação à pertinência do tema para o exercício da vida cidadã, a convivência democrática e a pluralidade de ideias, que igualmente justifica essa necessidade de novas pesquisas.

Outro aspecto pertinente evidenciado pela análise feita dos materiais mapeados foi sua concentração geográfica, que refletiu a persistente concentração do conhecimento científico em determinadas regiões e territórios do país. Como ressaltam Sidone et al. (2016, p. 16), no “[...] âmbito do sistema científico, é imprescindível fomentar a difusão da reconhecida excelência dos grandes centros urbanos do Sudeste para centros menos privilegiados de outras regiões de maneira a atenuar a intensa concentração regional das atividades ao longo do território nacional". Dessa forma, espera-se que os(as) pesquisadores(as), que agora por aqui terão contato com esse resultado, esforcem-se na superação da segmentação moral, ora competência moral, como um tópico quase exclusivo da pesquisa científica da região Sudeste brasileira.

Uma proposição para isso, tal como sugerem Hayashi e Guimarães (2016) e Sidone et al. (2016), seria a divulgação dos resultados dessas pesquisas em veículos acadêmicos, como em eventos científicos ou periódicos, localizados nas demais regiões com pouca incidência de materiais, proposição que, neste caso, não só se verifica como sugestão, mas também como necessidade. E isso se aplica aos resultados seguintes constatados, acerca da orientação das pesquisas stricto sensu e das Universidades que elas decorrem.

Com essa divulgação da competência e da segmentação moral e, para tanto, com o possível interesse despertado por pesquisadores(as) de outras regiões que as desconhecem, e muitos(as) deles(as) vinculados a PPGs, esses(as) poderão passar a desenvolver e orientar pesquisas sobre o tema, rompendo com essa concentração do conhecimento e, também, com a consequente endogenia em pesquisa (Sampaio \& Sanchez, 2017; Saravali, Guimarães \& Silva, 2017), que aqui se constataram. Este artigo, por exemplo, já se verifica como um agente nessa empreitada de divulgação da competência e da segmentação moral como temas emergentes para a pesquisa científica 
sobre moralidade, o qual é potencializado pela sua circulação por meio eletrônico/digital (Neto \& Araújo, 2019), justificando, em parte, a produção do artigo e consequente relevância nesse sentido.

\section{Considerações finais}

O mapeamento que se objetivou foi concluído com êxito. Expôs-se, então, as principais características da produção mapeada que os procedimentos do estado da arte permitiram entrar em contato. Sendo ela escassa e concentrada geograficamente (inclusive por determinadas Universidades e orientadores), aponta-se para $\mathrm{o}$ comprometimento de maior divulgação da competência e da segmentação moral em veículos acadêmicos por parte dos(as) pesquisadores(as) que já as estudam.

Ademais, dado o aumento das pesquisas no final do período de 2001-2019, ressalta-se o fato de que esse mapeamento se refere ao estado da produção tal como se encontra atualmente, sendo que futuramente poderá ser alterado e novos mapeamentos serão necessários. A produção de pesquisa é contínua, instável, numa característica mutabilidade, como se viu no intervalo de 2001 a 2008 desse período em que não houve nenhuma publicação de tese ou dissertação sobre o tema e que, ao contrário das expectativas, foi se transformando até chegar ao seu estado atual que, segundo o mapeamento ora apresentado, detém cerca de 30 materiais, 10 teses e 20 dissertações, além dos 04 artigos também encontrados.

Espera-se que o presente mapeamento sobre a segmentação moral na produção científica brasileira, erigido nos moldes do estado da arte, possa contribuir para o avanço das pesquisas que têm a competência moral, ou mesmo a moralidade em si, como objeto de estudo, bem como seja um pontapé inicial para outras investigações que, da mesma forma, busquem a inteligibilidade e reconhecimento dessa produção.

\section{Referências}

Almeida, E. C. E., \& Guimarães, J. A. (2017). A pós-graduação e a evolução da produção científica brasileira. São Paulo: Editora Senac. 
Bataglia, P. U. R. (2001). A construção da competência moral e a formação do psicólogo, (Tese de Doutorado). Retirado de https://repositorio.ufsc.br/handle/123456789/132604

Bataglia, P. U. R. (2010). A validação do teste de juízo moral (MJT) para diferentes culturas: o caso brasileiro. Psicologia: Reflexão e Crítica, 23(1), 83-91. http://dx.doi.org/10.1590/S0102-79722010000100011

Bataglia, P. U. R., Morais, A. de. \& Lepre, R. M. (2010). A teoria de Kohlberg sobre o desenvolvimento do raciocínio moral e os instrumentos de avaliação de juízo e competência moral em uso no Brasil. Estudos de Psicologia, Natal, 15(1), 25-32. https://doi.org/10.1590/S1413-294X2010000100004

Bataglia, P. U. R., Schillinger, M., \& Lind, G. (2006). Moral segmentation in MJT studies: cultural influences. Paper presented at the meeting of the Association for Moral Education, Fribourg, Switzerland.

Bataglia, P. U. R., Schillinger-Agati, M., Lind, G., \& Quevedo, T. L. (2003). Testing the segmentation hypothesis with an extended version of the MJT. Poster presented at the meeting of the Association for Moral Education, Krakow.

Bataglia, P. U. R., Schillinger-Agati, M., Torres, S. S., Crivelaro, D. B. Z., Oliveira, D. D., \& Quevedo, T. L. (2002). The development of moral competence and religious commitment in Brazil. Paper presented at the meeting of the Association for Moral Education, Chicago.

Colby, A. \& Kohlberg, L. (1987). The measurement of moral judgment: theoretical foundtation and research validation, v. 1. (Cambridge University Press, Cambridge, MA).

Dellazzana-Zanon, L. L., Bordini, G. S., Sperb, T. M., Freitas, L. B. de. (2013).

Pesquisas sobre desenvolvimento moral: contribuições da psicologia brasileira.

Psico, 44(3), pp. 342-351. Retirado de http://revistaseletronicas.pucrs.br/ojs/index.php/revistapsico/article/view/15821

Ferreira, N. S. de A. (2002). As pesquisas denominadas "estado da arte". Educação \& Sociedade, 23(79), 257-272. Retirado de http://www.scielo.br/pdf/es/v23n79/10857.pdf

Hayashi, M. C. P. I., \& Guimarães, V . A. L. (2016). A comunicação da ciência em eventos científicos na visão de pesquisadores. Em Questão, 22(3), 161-183. http://dx.doi.org/10.19132/1808-5245223.161-183 
Kohlberg, L. (2017). Resolving, moral conflicts within the just community. In: Harding,

C. G, Moral dilemmas and ethical reasoning (71-98). London/New York: Routledge.

Lind, G. (2003). Does religion foster or hamper morality and democracy?.

Recuperado de:

https://pdfs.semanticscholar.org/82a4/064786048193eaaa3cf32cbf2a95d0473d0f.pdf

Lind, G. (2019). How to teach moral competence. Berlin: Logos-Publisher.

Lind, G., \& Wakenhut, R. (2017). Testing for moral judgment competence. In Lind, G., Hartmann, H. A., \& Wakenhut, R. (Orgs.) Moral judgments and social education. Londres: Routledge. 25-48.

Maciel, F. I. P. (2014). Alfabetização no brasil: pesquisas, dados e análise. In Mortatti, M. do R. L.; Frade, I. C. A. da S. (Orgs.). Alfabetização e seus sentidos: o que sabemos, fazemos e queremos?. Marília: Oficina Universitária; São Paulo: Editora Unesp. 109-129.

Moreno, C. (2005). Moral education in higher education and the transformation of a concern: a historical account. Paper presented at the 31 st annual meeting or the Association for Moral Education, Cambridge.

Neto, L. F. P., \& Araújo, S. (2019). A divulgação científica na internet como garantidor do direito fundamental à educação nas eras da anticiência e da cibercultura. Revista de Estudos Jurídicos, 3, 27-48. Retirado de http://revistas.unirn.edu.br/index.php/revistajuridica/article/view/652

Nobre, L. N., \& Freitas, R. R. (2017). A evolução da pós-graduação no Brasil: histórico, políticas e avaliação. Brazilian Journal of Production Engineering - BJPE, 3(2), 26-39. Retirado de https://periodicos.ufes.br/bjpe/article/view/v3n2_3

Romanowski, J. P.; Ens, R. T. (2006). As pesquisas denominadas do tipo "estado da arte” em educação. Diálogo Educ., 6 (19), 37-50. Retirado de https://www.redalyc.org/articulo.oa?id=189116275004

Sampaio, H., \& Sanchez, I. (2017). Formação acadêmica e atuação profissional de docentes em educação: USP e Unicamp. Cadernos de Pesquisa, 47(166), 12681291. https://doi.org/10.1590/198053144495

Saravali, E. G., Guimarães, T., \& Silva, R. C. da. (2017). Pesquisas sobre a construção do conhecimento social no contexto brasileiro: estado da arte 2005-2017. Ensino Em Re-Vista, 25(1), 33-56. https://dx.doi.org/10.14393ER-v25n1a2018-02 
Senger, R. (1985). Segmentation of soldiers' moral judgment. In Lind, G., Hartmann, H A., \& Wakenhut, R. (Orgs.). Moral development and the social environment. Chicago: Precedent Publishers. 221-242.

Sidone, O. J. G., Haddad, E. A., \& Mena-Chalco, J. P. (2016). A ciência nas regiões brasileiras: evolução da produção e das redes de colaboração científica.

TransInformação, 28(1), 15-31. http://dx.doi.org/10.1590/2318$08892016002800002 \% 20$

Silva, M. E. F da, \& Bataglia, P. U. R. (2020). [Instrumento de pesquisa]. Pesquisas brasileiras sobre segmentação moral em artigos e teses e dissertações (20012019): um instrumento de pesquisa. $128 \mathrm{f}$.

Souza, M. G. T. de, Souza, B. C. de, Bilsky, W., \& Roazzi, A. (2016). The culture of honor as the best explanation for the high rates of criminal homicide in Pernambuco: A comparative study with 160 convicts and non-convicts. Anuario de Psicología Jurídica, 26(1), 114-121. https://doi.org/10.1016/j.apj.2015.03.001

Thoma, S. J., Bebeau, M. J., \& Narvaez, D. (2016). How not to evaluate a psychological measure: Rebuttal to criticism of the Defining Issues Test of moral judgment development by Curzer and colleagues. Theory and Research in Education, 14(2), 241-249. https://doi.org/10.1177/1477878516635365

Submetido em: 07/05/2020

Aprovado em: 09/07/2020 